\title{
Prevalence of hepatitis C virus genotypes in south-central Sicily, Italy: a comparative study between 2000/2001 and 2010/2014
}

\author{
Liborio Bellomo, Rosalba Collodoro, Giuseppina Di Forti, Salvatrice Mancuso, \\ Alessandra D. Russo
}

Virology Unit, Local Health 2, Caltanissetta, Italy

\section{Summary}

The aim of this study is to evaluate the prevalence of various genotypes in the population of south-central Sicily (Italy) and to compare recent data with those of 2000/2001. In 2000, the patients tested were 202, all hepatitis $\mathrm{C}$ virus (HCV)-RNA and anti-HCV positive. From 2010 to 2014 the patients examined are in total 535, all anti-HCV positive, but 111 with genotype negative and therefore likely HCV-RNA negative. The study showed a clear predominance of genotype $1 \mathrm{~b}$ for both men and women, however, with a much greater prevalence in the older cohort. In both groups, then, the 3 a genotype follows for men, while the $2 \mathrm{a} / 2 \mathrm{c}$ follows for women. 1a genotype prevalence rate falls in the most recent group of women. The cases of co-infection of more genotypes remain very content in 2014 as it happened in 2000.

\section{Introduction}

The hepatitis $\mathrm{C}$ virus (HCV) infects more than 170 million people all over the world and it is an important etiologic agent of cirrhosis

Correspondence: Liborio Bellomo, Local Helth 2, Via L. Russo 6, 93100 Caltanissetta, Italy.

Tel.: +39.0934.559555 - Fax: +39.0934 .559551 .

E-mail: liboriobellomo@virgilio.it

Key words: Genotype; hepatitis C virus; prevalence.

Acknowledgements: authors would thank Miss Antonella Lattuca for the valuable and effective collaboration and Miss Claudia Lo Magno for the kind contribution.

Contributions: the authors contributed equally.

Conflict of interest: the authors declare no potential conflict of interest.

Received for publication: 27 October 2015.

Revision received: 25 February 2016.

Accepted for publication: 18 March 2016.

(C) Copyright L. Bellomo et al., 2016

Licensee PAGEPress, Italy

Microbiologia Medica 2016; 31:5606

doi: $10.4081 / \mathrm{mm} .2016 .5606$

This article is distributed under the terms of the Creative Commons Attribution Noncommercial License (by-nc 4.0) which permits any noncommercial use, distribution, and reproduction in any medium, provided the original author(s) and source are credited. and hepato-cellular carcinoma (HCC). This is a fairly common cancer (5th place in the world) and it is in the 3rd place as a cause of cancer death (1).

Italy is the European country with the highest prevalence that varies according to regionality from $3 \%$ to $26 \%$ with a progressive increase in relation to age; the disease is most represented in the South and in Islands $(4,5)$.

Hepatitis $\mathrm{C}$ is a virus with hepato-tropism and it is transmitted parenterally. It presents a genome with a significant degree of variability, since the RNA dependent RNA polymerase makes mistakes during the phase of replication.

The most conserved regions are those of the core and 5' UTR, instead the genomic regions that encode for the synthesis of E1-E2 are subject to greater variations.

According to the percentage of similarity among the nucleotide sequences the HCV differs in genotypes (30\%), subtypes (10\%) and quasi-species (5\%).

The geographical distribution of genotypes is as it follows: $1 \mathrm{~b}$ is present throughout the world; 1a and 3a in Europe and in North America; 2 in the Mediterranean, in Far East and in West Africa; 4 in the Middle East and Central Africa; 5 in South Africa; 6 in South East Asia; 7, the latest insulation, in the Democratic Republic of Congo.

Studies led by the association between genotype and route of transmission show that the $1 \mathrm{~b}$ and $2 \mathrm{a} / 2 \mathrm{c}$ seem to be more prevalent among people with multiple transfusions or sporadic infection, furthermore genotypes 1a and $3 \mathrm{a}$ are more frequent among drug addicts.

There is also an association with age: $1 \mathrm{~b}$ and $2 \mathrm{a} / 2 \mathrm{c}$ genotype are mostly found in older people, while 1a and 3a genotype are found mainly in young people. Furthermore genotype $3 \mathrm{a}$ is considered more recently spread if compared to $1 \mathrm{~b}$ and $2 \mathrm{a} / 2 \mathrm{c}(3,5-11)$.

In recent years there has been an increase in the insulation of the 4 genotype (prevalent in North Africa) in the Mediterranean areas such as Spain, Greece, France and especially Italy, where previously it was quite rare. This genotype is remarkable in clinical practice as it is more resistant to classical antiviral therapy (interferon alfa and ribavirin), and it is frequently associated with the development of cirrhosis and hepatocellular carcinoma (3-5). The clinical utility of HCV genotype tests is related to the optimal dosage of the therapy, as well it is related to the duration of treatment.

\section{Materials and Methods}

The study area in which this U.O. works includes areas of southcentral Sicily.

Patients examined from 2010 to 2014 are in total 535 of which 343 men, 175 women and 17 are carriers of HIV infection. In the study, there were included European and non-European patients aged 
between 51 and 63, all anti-HCV positive; 424 are HCV-RNA positive and with liver disease, while 111 are negative for HCV genotype tests and therefore likely negative for HCV-RNA tests. Data for 2000/2001 are taken from a previous study, conducted on European patients, concerning with the same basin: 202 patients with liver disease, anti-HCV positive and HCV-RNA positive (2).

The determination of the genotype for the patients tested in 2010/2014 was carried out with the VERSANT HCV Genotype 2.0 Assay (LiPA) kit of Siemens Healthineers (Erlangen, Germany) which uses an intermediate product of biotinylated DNA specific for 5' UTR and CORE regions of the HCV genome, as it was obtained using the VERSANT HCV Amplification 2.0 (LIPA) after extraction of viral RNA.

The VERSANT HCV Genotype 2.0 Assay (LiPA) uses the reverse hybridization, which identifies genotypes and subtypes 1-6.

Patients in 2000, tested with the HCV Genotype III Nuclear Laser Medicine, are 202, all with liver disease, anti-HCV and HCV-RNA positive and they show the following numbers and percentage distinguished by gender and genotype.

\section{Results}

\section{$2001 / 2001$}

Data taken from the previous study, referring to the period 20002001, are reported in Table 1 (total 122 patients).

\section{$2010 / 2014$}

HCV-RNA positive patients are 424, while negatives are 111 and represent respectively $79.25 \%$ and $20.75 \%$. The prevalence percentage of various genotypes that was observed in 2010/2014 patients cohort is shown in Figure 1.

Data were distinguished by gender; results differentiated by genotypes percentage and number are shown in Table 2, while the number of HIV negative $v$ s. positive patients is shown in Table 3 . The percentage and number of European vs. non-European patients is shown in Figure 2 and Table 4.

\section{Statistical analysis}

We compared male and female cohorts in the two periods for genotypes 1b, 3a, 1a, 2a/2c, 4c/4d, 1a/1b. We applied chi-square test that has given statistical significance only for the genotype $1 \mathrm{~b}$ group of men $(\mathrm{P}<0.001)$. This genotype has more prevalence in older cohort. Due to the low number of HIV positive patients and non-European patients, we have not examined them.

\section{Discussion and Conclusions}

1b genotype is found more frequently in 2000 than in 2014 although lb genotype has a much higher prevalence in the older group male (statistical significance: $\mathrm{P}<0.001$ ); $3 \mathrm{a}$ genotype for men and $2 \mathrm{a} / 2 \mathrm{c}$

Table 1. 2000/2001 patients cohort.

\begin{tabular}{|c|c|c|c|c|c|c|}
\hline \multirow[t]{2}{*}{ Genotype } & \multicolumn{2}{|c|}{ Total } & \multicolumn{2}{|c|}{ Men } & \multicolumn{2}{|c|}{ Women } \\
\hline & $\%$ & N. & $\%$ & N. & $\%$ & N. \\
\hline $1 b$ & 60.30 & 122 & 62.30 & 76 & 37.70 & 46 \\
\hline $3 \mathrm{a}$ & 13.90 & 28 & 89.29 & 25 & 10.71 & 3 \\
\hline la & 10.90 & 22 & 81.82 & 18 & 18.18 & 4 \\
\hline $2 a / 2 c$ & 10.40 & 21 & 57.14 & 12 & 42.86 & 9 \\
\hline $4 \mathrm{c} / 4 \mathrm{~d}$ & 3.50 & 7 & 71.43 & 5 & 28.57 & 2 \\
\hline $1 a+1 b$ & 1.00 & 2 & 0.00 & 0 & 100.00 & 2 \\
\hline
\end{tabular}

Table 2. Patients differentiated by genotypes.

\begin{tabular}{|c|c|c|c|c|c|}
\hline \multirow[t]{2}{*}{ Genotype } & \multicolumn{2}{|c|}{ Men } & \multicolumn{2}{|c|}{ Women } & \multirow[t]{2}{*}{ Tota } \\
\hline & $\%$ & N. & $\%$ & N. & \\
\hline $1 b$ & 36.67 & 99 & 57.55 & 80 & 179 \\
\hline 1 & 2.22 & 6 & 0.00 & 0 & 6 \\
\hline 2 & 1.11 & 3 & 0.72 & 1 & 4 \\
\hline 3 & 0.37 & 1 & 0.00 & 0 & 1 \\
\hline 4 & 0.74 & 2 & 2.16 & 3 & 5 \\
\hline $1+3 a$ & 0.37 & 1 & 0.00 & 0 & 1 \\
\hline la & 16.30 & 44 & 7.19 & 10 & 54 \\
\hline $1 \mathrm{a} / \mathrm{lb}$ & 0.37 & 1 & 3.60 & 5 & 6 \\
\hline $2 a / 2 c$ & 8.15 & 22 & 15.11 & 21 & 43 \\
\hline $2 b$ & 1.11 & 3 & 0.72 & 1 & 4 \\
\hline $3 a$ & 27.78 & 75 & 7.91 & 11 & 86 \\
\hline $4 a / 4 c / 4 d$ & 3.33 & 9 & 4.32 & 6 & 15 \\
\hline $5 a$ & 1.48 & 4 & 0.72 & 1 & 5 \\
\hline
\end{tabular}

Table 3. HIV negative patients $v s$. HIV positive patients.

\begin{tabular}{|c|c|c|c|c|}
\hline \multirow[t]{2}{*}{ Genotype } & \multicolumn{2}{|c|}{ HIV negative patients } & \multicolumn{2}{|c|}{ HIV positive patients } \\
\hline & N. & $\%$ & N. & $\%$ \\
\hline $1 b$ & 179 & 43.77 & 0 & 0.00 \\
\hline 1 & 6 & 1.47 & 0 & 0.00 \\
\hline 2 & 4 & 0.98 & 0 & 0.00 \\
\hline 3 & 1 & 0.24 & 0 & 0.00 \\
\hline 4 & 5 & 1.22 & 0 & 0.00 \\
\hline $1+3 a$ & 1 & 0.24 & 0 & 0.00 \\
\hline la & 54 & 13.20 & 7 & 46.66 \\
\hline $1 \mathrm{a} / \mathrm{lb}$ & 6 & 1.47 & 1 & 6.67 \\
\hline $2 a / 2 c$ & 43 & 10.51 & 1 & 6.67 \\
\hline $2 b$ & 4 & 0.98 & 0 & 0.00 \\
\hline 3a & 86 & 21.03 & 6 & 40.00 \\
\hline $4 \mathrm{a} / 4 \mathrm{c} / 4 \mathrm{~d}$ & 15 & 3.67 & 0 & 0.00 \\
\hline $5 \mathrm{a}$ & 5 & 1.22 & 0 & 0.00 \\
\hline
\end{tabular}




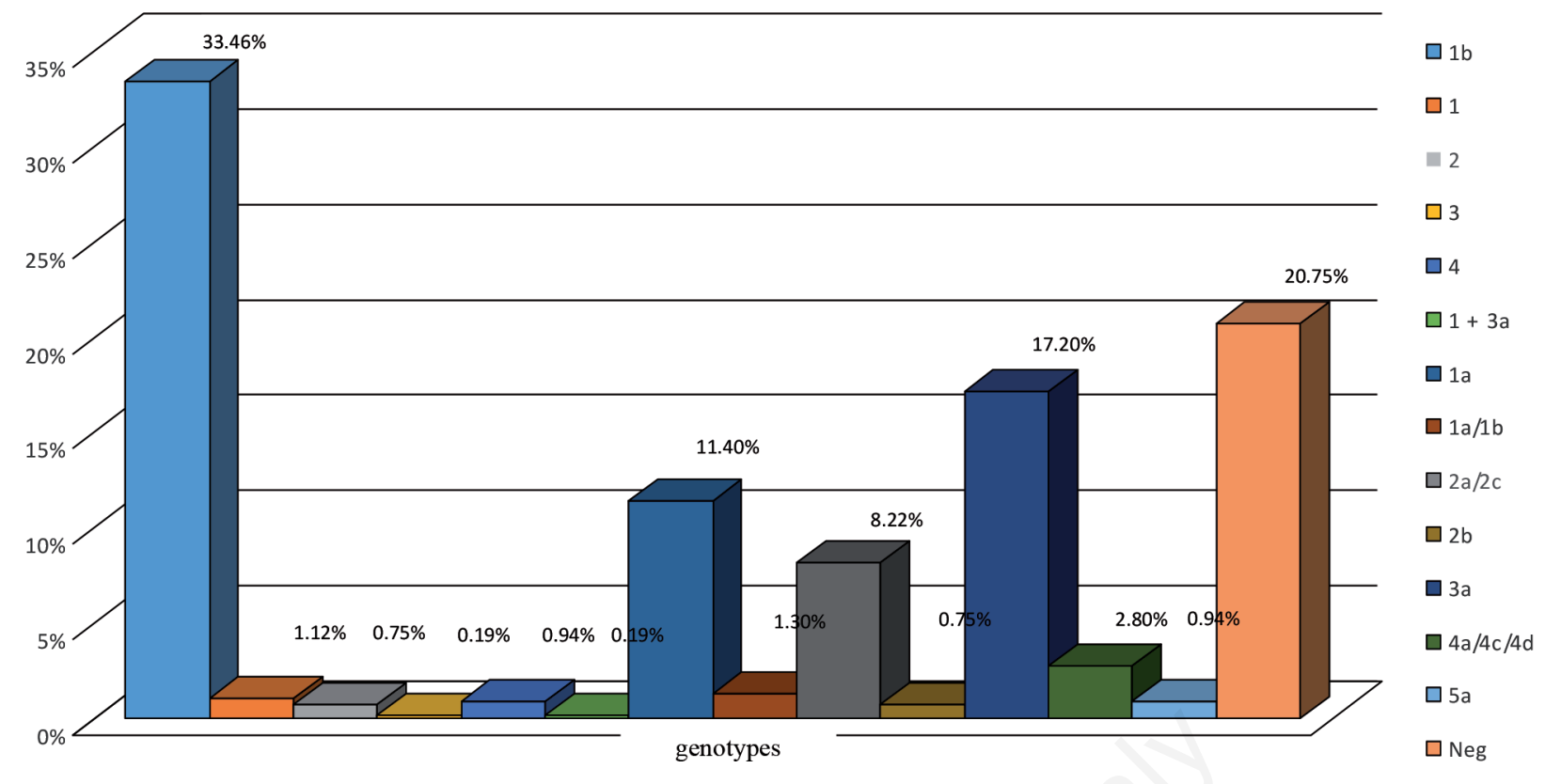

Figure 1. Hepatitis $\mathrm{C}$ virus genotypes prevalence.

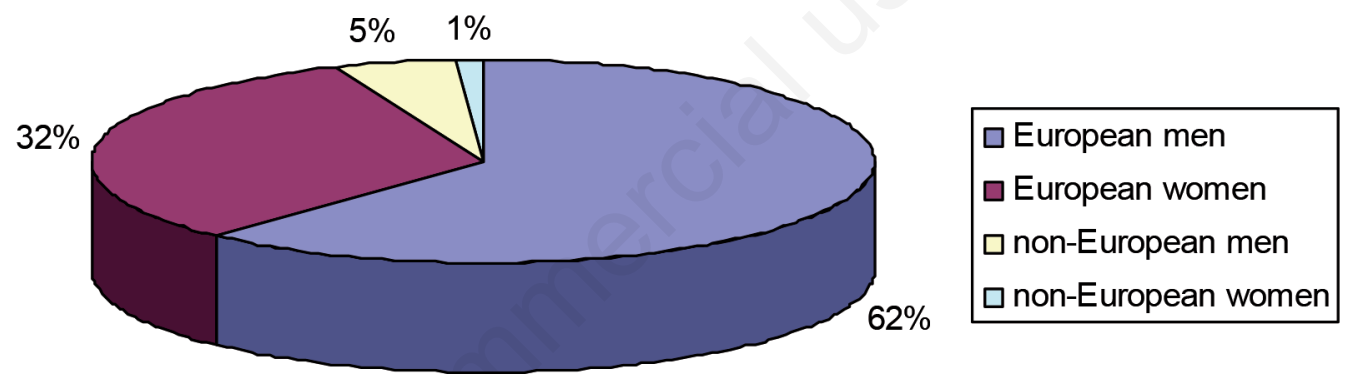

Figure 2. European patients $v s$. non-European patients.

Table 4. European patients vs. non-European patients.

\begin{tabular}{|c|c|c|c|c|c|c|c|c|c|}
\hline \multirow{2}{*}{ Genotype } & \multicolumn{4}{|c|}{ European patients } & \multicolumn{4}{|c|}{ non-European patients } & \multirow{2}{*}{ Total } \\
\hline & Men, N. & Men, $\%$ & Women, N. & Women, \% & Men, N. & Men, $\%$ & Women, N. & Women, \% & \\
\hline $1 b$ & 98 & 36.30 & 78 & 57.35 & 1 & 6.67 & 2 & 66.67 & 179 \\
\hline 1 & 6 & 2.22 & 0 & 0.00 & 0 & 0.00 & 0 & 0.00 & 6 \\
\hline 2 & 3 & 1.11 & 1 & 0.73 & 0 & 0.00 & 0 & 0.00 & 4 \\
\hline 3 & 1 & 0.37 & 0 & 0.00 & 0 & 0.00 & 0 & 0.00 & 1 \\
\hline 4 & 2 & 0.74 & 3 & 2.21 & 0 & 0.00 & 0 & 0.00 & 5 \\
\hline $1+3 \mathrm{a}$ & 1 & 0.37 & 0 & 0.00 & 0 & 0.00 & 0 & 0.00 & 1 \\
\hline la & 43 & 15.93 & 10 & 7.35 & 8 & 53.33 & 0 & 0.00 & 61 \\
\hline $1 \mathrm{a} / 1 \mathrm{~b}$ & 2 & 0.74 & 5 & 3.70 & 0 & 0.00 & 0 & 0.00 & 7 \\
\hline $2 \mathrm{a} / 2 \mathrm{c}$ & 23 & 8.52 & 21 & 15.44 & 0 & 0.00 & 0 & 0.00 & 44 \\
\hline $2 b$ & 3 & 1.11 & 1 & 0.73 & 0 & 0.00 & 0 & 0.00 & 4 \\
\hline $3 a$ & 75 & 27.78 & 10 & 7.35 & 6 & 40.00 & 1 & 33.33 & 92 \\
\hline $4 \mathrm{a} / 4 \mathrm{c} / 4 \mathrm{~d}$ & 9 & 3.33 & 6 & 4.41 & 0 & 0.00 & 0 & 0.00 & 15 \\
\hline $5 a$ & 4 & 1.48 & 1 & 0.73 & 0 & 0.00 & 0 & 0.00 & 5 \\
\hline
\end{tabular}


genotype for women follow in both 2000 and in 2014. Then, women's group in 2014 has $3 \mathrm{a}$ genotype and la genotype with the same prevalence opposed to 2000, when la genotype was most represented; while, as regards the men, la genotype follows in 2000 and 2014.

The higher prevalence of $1 \mathrm{~b}$ genotype in the oldest group is probably due to the particular regionality, to the greatest resistance to therapy that caused the genotype to work much and to the recent migration flow.

By comparing data from the two groups, the genotype most represented in the two genders results always $1 \mathrm{~b}$; immediately after, the two sexes, instead, differ in a higher prevalence of 3 a genotype in men and $2 \mathrm{a} / 2 \mathrm{c}$ genotype in women.

In 2014, the patients with HIV infection have most frequently la and 3 a genotype.

non-European male patients have most often genotype 1a and 3a, while non-European women have $1 \mathrm{~b}$ and $3 \mathrm{a}$. We can not make a statistical study for non-European and HIV carriers, because the patients are few.

We have a case of co-infection with contemporary presence of 1 and 3 a genotype only in the 2014 group.

It was not possible to obtain any data about the contagion mode, time of infection for all patients. Furthermore, it was not possible to know the regions of origin of non-European patients.

Among the 535 samples tested in 2014, 79.25\% of patients were positive and $20.75 \%$ were negative.

Negative patients are due likely to therapy, prescriptive appropriateness, tests performed on patients with certain life styles (e.g. promiscuous sex), with particular diseases (e.g. immunocompromised, politransfused), time infection, etc.

In any case, we intend soon to be able to cut down the negative amount also optimizing requests of prescribers through a growing awareness and an education to appropriate prescription. Therefore, it will be appropriate to re-evaluate these data in the future in order to consider the effects of the massive and recent migration and to continue studies about HIV positive and non-European patients.

\section{References}

1. Alisi A, Arciello M, Petrini S, et al. Focal adhesion kinase (FAK) mediates the induction of pro-oncogenic and fibrogenic phenoypes in hepatitis C virus (HCV)-infected cells. Plos One 2012;7:441-7.

2. Bellomo L, Miraglia IM. Prevalence of HCV genotypes in south-central Sicily. Microbiol Med 2003;18:45-6.

3. Coppola N, Diodato AM, Petruzziello A, et al. Age and gender distribution of hepatitis $\mathrm{C}$ virus genotypes in metropolitan area of Naples. Intervirology 2013;19:3207-12.

4. Fenoglio L, Serraino C, Castagna E, et al. Epidemiology, clinicaltreatment patterns and outcome in 256 hepatocellular carcinoma cases. World J. Gatroenterol 2013;19:3207-16.

5. Gower E, Estes C, Blach S, Razavy H. Global epidemiology and genotype distribution of hepatitis C virus infection. J. Hepatol 2014:45-57.

6. Marascio N, Matera G, Lamberti AG, et al. Increase in the prevalence of infection with hepatitis $\mathrm{C}$ virus genotype 4 in Calabria. Available from: www.epicentdro.iss.it/ben/2011/aprile/1.asp

7. Marascio A, Matera G, Quirino A, et al. Eleven-years distribution pattern of hepatitis $\mathrm{C}$ virus in Southern Italy. J Pathogens 2012;2012:631095.

8. Marascio N, Liberto MC, Barecca GS, et al. Update on epidemiology of HCV in Italy: focus on Calabrian region. BMC Infect Dis 2014;14:52-5.

9. Petruzziello A, Coppola N, Loquercio G, et al. Distribution patterns of hepatitis $\mathrm{C}$ virus genotypes and correlation with viral load and risk factors in chronic positive patients. Intervirology 2014:311-8.

10. Smith DB, Bukh J, Muerhoff AG, et al. Expanded classification of hepatitis $\mathrm{C}$ virus into 7 genotypes and 67 subtypes: updated criteria an genotype assignment web resource. Hepatology 2014;59:318-27.

11. Sodano G, Cuomo N, Di Nicuolo G, et al. Distribution of HCV genotypes in the metropolitan area of Naples. Microbiologia Medica 2013;28:2. 